\title{
PRÁTICAS REFLEXIVAS SOBRE CRENÇAS NO PROCESSO DE ENSINO- APRENDIZAGEM DE LÍNGUAS E CULTURAS: ANALISANDO CRENÇAS CULTURAIS NO CURSO DE LETRAS DA UEFS
}

\author{
José Railson da Silva Costa ${ }^{1}$; Milenna Brun ${ }^{2}$ \\ 1. Bolsista PIBIC/CNPq, Graduando em Letras com inglês, Universidade Estadual de Feira de Santana, e-mail: railson- \\ costa3@hotmail.com \\ 2. Orientador, Departamento de Letras e Artes, Universidade Estadual de Feira de Santana, e-mail: milennab@uefs.br
}

PALAVRAS-CHAVE: crenças; cultura; alteridade.

\section{INTRODUÇÃO}

O contexto de aprendizagem de uma língua estrangeira envolve elementos linguísticos, culturais e sociais que permitem aos estudantes ampliar a consciência sobre o espaço e a cultura do outro de forma mais consciente, além de ser um espaço que o estudante de língua estrangeira já chega com crenças sobre o que seja ensinar e aprender uma língua estrangeira, de forma já preestabelecida. Algumas crenças no entanto, podem ser resignificadas e influenciar positivamente ou não o aprimoramento linguístico e cultural dos estudantes, a depender da postura crítica do professor de línguas.

Diante da complexidade do ensino de língua estrangeira, muitos pesquisadores têm conceituado crenças e a importância da sua pesquisa para a linguística aplicada e para as metodologias de ensino de língua. Um dos precursores da investigação sobre crenças e de sua relação com o conhecimento foi o filósofo americano John Dewey (1933). Sua postulação de crenças como fruto da experiência humana serviu de base teórica para as pesquisas subsequentes. Na década de $80 \mathrm{com}$ os avanços da linguística aplicada, uma grande gama de pesquisas sobre crenças no ensino de línguas foram desenvolvidas dando origem a diversas conceituações.

As crenças dos estudantes e professores podem ser opiniões (Wenden, 1986) ou representações (Holec, 1987) sobre como se estuda ou se usa uma língua estrangeira (Almeida Filho, 1993). A pesquisadora pioneira nesse tipo de pesquisa foi Elaine Horwitz (1988) que conceituou as crenças como ideias equivocadas que, se forem positivas, podem estimular a aprendizagem de línguas. Horwitz (1988) elaborou um dos instrumentos mais utilizados para investigar quantitativamente as crenças de estudantes e professores de línguas. O inventário BALLI (Beliefs About Language Learning Invetory) é um questionário com 34 perguntas sobre as crenças de professores e alunos sobre línguas estrangeiras organizadas numa escala likert.

O objetivo geral deste segmento da pesquisa longitudinal coordenada pelo Grupo ELCE (Educação Línguas e Culturas Estrangeiras) ${ }^{1}$ é mapear as crenças culturais de professores e alunos dos cursos de letras da Universidade Estadual de Feira de Santana (UEFS). O intuito é buscar melhorias no curso de graduação e possibilitar reflexões dos professores e estudantes sobre o papel das crenças culturais na sua formação para a alteridade e inclusão social considerando que as crenças não se restringem apenas a contextos educacionais podendo existir dentro e fora da sala de aula (Pajares, 1992; Barcelos, 2004). Ao revisar pesquisas sobre crenças culturais, Rozenfeld (2007) afirma que a experiência, a vivência cultural e a bagagem emocional também interferem no processo de ensino-aprendizagem de línguas estrangeiras, e, por isso, enfatiza a importância de realizar pesquisas sobre crenças em um viés que não seja puramente linguístico.

A metodologia da pesquisa consistiu em um levantamento das crenças culturais de professores e alunos dos cursos de letras da UEFS nos semestre 2017.2 e 2018.1.

\footnotetext{
${ }^{1}$ http://www.elce.uefs.br/modules/conteudo/conteudo.php?conteudo=7
} 


\section{MATERIAL E MÉTODOS OU METODOLOGIA}

A metodologia da pesquisa encontra-se descrita detalhadamente no artigo de Brun (2017). O estudo visa fazer um levantamento quali-quantitativo longitudinal das crenças dos professores e alunos do curso de letras vernáculas, inglês, espanhol e francês no período de 2017/2020.

Este segmento do estudo utilizou os dados coletados através do questionário BALLI para analisar as crenças culturais de 55 alunos dos cursos de licenciatura em Línguas Estrangeiras e 18 professores de Linguística e Línguas Estrangeiras do DLA. A variável principal (crenças de professores e alunos acerca do Processo de Ensino e Aprendizagem de Línguas Estrangeiras) é composta de cinco indicadores e este trabalho focalizou de maneira comparativa os aspectos culturais das crenças de professores e de alunos dos cursos de estrangeiras (não estão aqui computados as crenças dos alunos de Letras vernáculas). Considerando o pequeno número de sujeitos e a consequente impossibilidade de proceder à uma análise fatorial, foram utilizadas as análises estatísticas publicadas em 20 estudos quantitativos com esta temática e este instrumento de coleta de dados (BALLI). As afirmativas foram assim selecionadas para cada indicador. Para a investigação das crenças culturais, foram comparadas as crenças de alunos e professores abordadas nas questões $8,10,12$ do questionário Balli versão aluno (que correspondem às questões 2, 4 e 6 do questionário Balli versão professor). Também foram examinadas as questões 13 e 24 do questionário versão aluno.

\section{RESULTADOS E/OU DISCUSSÃO}

No que se diz respeito às crenças culturais, a autora Rozenfeld (2007) agrupa as crenças culturais em três categorias: crenças tipicalizadas, crenças comparativas e crenças relativizadas. A autora traçou essa classificações, baseando-se no estudos de Weinrich (1998), Todorov (1995, citado por Dornbusch, 1999) e Dornbusch (1999). Os referenciais utilizados como suporte para a categorização das crenças discutem como ocorre o processo pelo qual o sujeito passa até chegar de fato na alteridade e no respeito à cultura do outro. Eles discutem também, como os estranhamentos culturais interferem nas práticas pedagógicas e como o estranhamento da língua e da cultura estrangeira pode levar ao distanciamento em relação ao outro indivíduo ou não.

Para Rozenfeld (2007), as crenças tipicalizadas se configuram a partir de estereótipos criados coletivamente em relação a um determinado povo. Essas crenças podem ser positivas ou negativas, mas sempre são marcadas por imagens preconcebidas, mitos e estereótipos. As crenças comparativas são as criadas pela comparação entre a língua-cultura materna e a línguacultura-alvo. As crenças relativizadas por sua vez se configuram por serem mistas, pois segundo a autora, estas são as crenças tipicalizadas em processo de ressignificação de algum clichê em relação à língua-cultura alvo. As crenças relativizadas apresentam um caráter positivo, pois há uma superação dos estereótipos construídos socialmente sobre um povo e sua língua.

A análise de dados indica que 78\% dos professores e 53\% dos alunos acreditam que é importante conhecer a cultura do falante para aprender a língua alvo. Percebem assim que a língua não pode ser aprendida pelo viés puramente linguístico. É relevante nesse aspecto assinalar que nenhum professor discordou dessa afirmativa e espera-se que no decorrer do curso esta noção seja internalizada pelos alunos. Mais de 60\% dos professores e estudantes concordam que é mais fácil aprender uma terceira língua quando já se sabe uma língua estrangeira. Os dois grupos apresentam também percepções semelhantes sobre as vantagens de aprender uma L2 no exterior. Apenas 39\% dos professores e $45 \%$ dos alunos concordam com essa necessidade (Cf. Gráfico 1). 
O gráfico 1 representa comparativamente as 3 questões selecionadas do BALLI que se referem a questões culturais sobre o aprendizado de línguas estrangeiras:

Q8 Aluno/Q2 Professor: "É necessário conhecer a cultura dos povos autóctones para falar uma língua estrangeira.";

Q10 Aluno/Q4 Professor: "É mais fácil aprender uma segunda ou terceira língua para alguém que já aprendeu uma língua estrangeira"

Q12 Aluno/Q6 Professor: "É melhor aprender uma língua estrangeira no país estrangeiro."

Gráfico 1: Representação comparativa das crenças de alunos de inglês, francês e espanhol e de professores de da Linguística e Línguas Estrangeiras do DLA

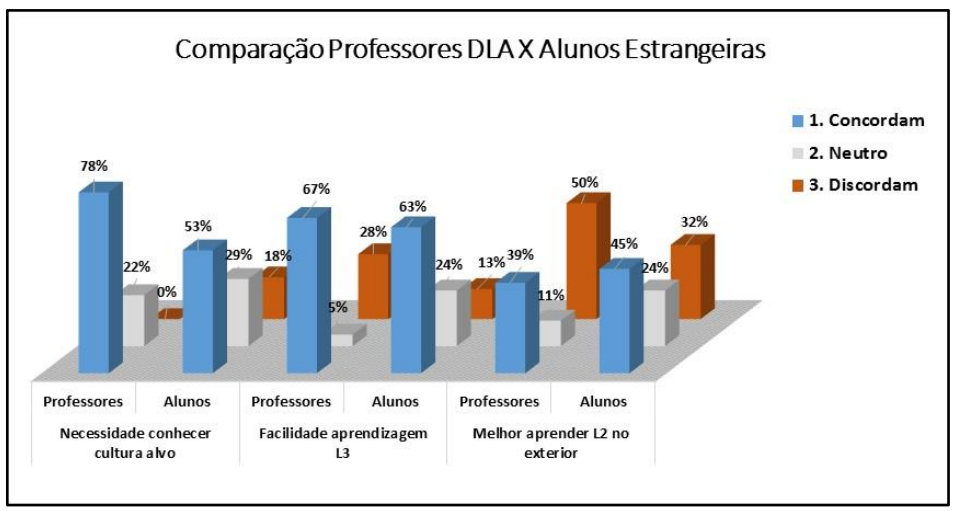

Fonte: Elaborado pelos autores

Os resultados também apontam para indícios alentadores acerca da motivação intrínseca dos alunos e a abertura para se relacionar com falantes da lîngua alvo: $82 \%$ afirmam gostar de praticar a língua com nativos e $68 \%$ declaram o desejo de aprender uma L2 para conhecer os falantes dessa língua (Cf. Gráfico 2).

O gráfico 2 representa 2 questões selecionadas do BALLI versão aluno sobre a abertura para entrar em contato com falantes nativos da língua alvo estudada.

Gráfico 2: Representação das crenças de alunos de inglês, francês e espanhol sobre a abertura para o contato com falantes nativos da L2

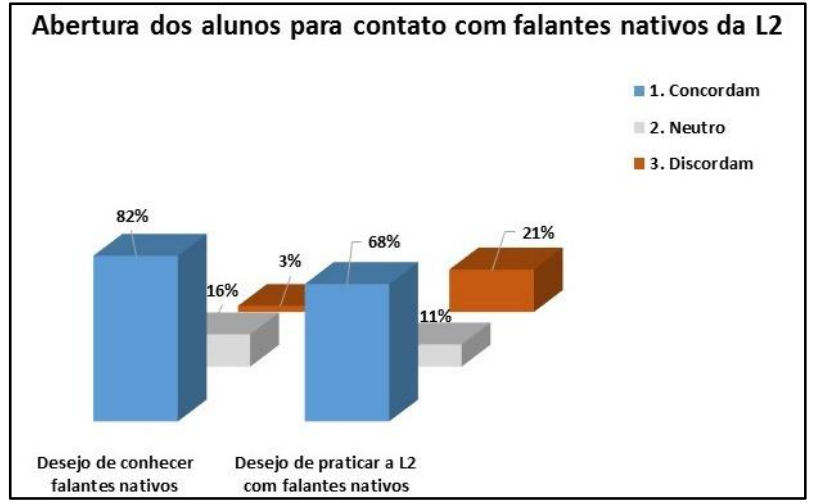

Fonte: Elaborado pelos autores

De forma geral, os participantes da pesquisa se mostraram abertos às possibilidades de convivência e de novos espaços de interação, pois as questões que eles concordaram tendem a ser crenças relativizadas. A partir da relação que Rozenfeld (2007) faz com as crenças culturais e suas classificações, nota-se que os estudantes de letras da UEFS no contexto de calouros mostram-se interessados no novo, na cultura e na língua do estrangeiro para contribuir para sua experiência com língua estrangeira.

Os estudantes de letras se mostram interessados em conhecer povos de outras culturas através do aprendizado de uma L2, como representam os dados no gráfico acima. Isso demonstra que há uma preocupação com o aspecto cultural o desejo de se inserirem em outras 
realidades. Contudo, é importante fomentar debates sobre a imersão cultural desses futuros professores de línguas, pois autores como Kramsch (1993), Almeida Filho (1993), Stierstorfer (2002) pontuam a necessidade de utilização da língua de forma social e a cultura deve aparecer no processo de aprendizado de uma língua como um plano de fundo como forma de mediação entre o aspecto linguístico e o contextual. O conhecimento sobre a cultura do outro se torna um fator essencial para evitar estranhamentos e resistências em relação a língua estrangeira.

O estudo apoia a criação de uma base de dados sobre crenças de professores e alunos sobre processos de aprendizagem na universidade evidenciando como as suposições sobre ensino e aprendizagem de línguas estrangeiras são construídas, disseminadas e podem influenciar positiva ou negativamente neste processo. Enfim, a consolidação das atividades do grupo de pesquisa ELCE (Educação Línguas e Culturas Estrangeiras) no campo do ensinoaprendizagem de línguas fundamenta a prática educativa no contexto das Licenciaturas em Línguas Estrangeiras e Culturas Estrangeiras na Uefs.

\section{CONSIDERAÇÕES FINAIS}

Esta primeira pesquisa sobre crenças do processo de ensino-aprendizagem de línguas e culturas estrangeiras desenvolvida no Departamento de Letras e Artes da UEFS representa um passo importante para a melhoria do curso de graduação em Letras. É notório que o curso precisa passar por mudanças e pesquisas dessa natureza incentivam os próprios sujeitos participantes a refletir sobre esta temática e dar continuidade à investigações sobre a formação de professores encorajando novas posturas no processo de ensino-aprendizagem de língua e culturas. Dessa forma, estarão conscientes do impacto das suas crenças para a aquisição linguística e desenvolvimento da alteridade quando em contato com novos sujeitos, novas realidades e novas formas de pensar.

\section{REFERÊNCIAS}

ALMEIDA FILHO, J.C.P Dimensões comunicativas no ensino de línguas. Campinas: Pontes, 1993. BARCELOS, A. M. F. Crenças sobre aprendizagem de línguas, Lingüística Aplicada e ensino de língua. Linguagem \& Ensino, Vol. 7, No. 1, 2004 (123-156).

BRUN, M. Estudo das crenças de professores e alunos dos cursos de Licenciatura em Letras da Uefs sobre o processo de aprendizagem: oportunizando caminhos de pesquisa. A Cor das Letras, v. 16, n. 1, p. 58-60, 2017.

DORNBUSCH, C. O olhar estrangeiro. Pandemonium Germanicum, n.2, p.13-21, 1998.

HOLEC, H. The learner as manager: managing learning or managing to learn? In A. Wenden \& J. Rubin (orgs.), Learner strategies in language learning London: Prentice Hall, p. 145-156, 1987.

HORWITZ, E. (1988). The beliefs about language learning of beginning university foreign language students. The Modern Language Journal, 72, 283-294.

KRAMSCH, C. Context and culture in language teaching. Oxford: OUP, 1993, 304 p.

PAJARES, F. M. Teacher's beliefs and educational research: cleaning up a messy construct. Review of Educational Research, v. 62, n.3, p. 307-332, 1992.

ROZENFELD, C. C. F. Crenças sobre uma língua e cultura alvo (alemã) em dimensão intercultural de ensino de língua estrangeira. 2008. Dissertação (mestrado em linguística) Universidade Federal de São Carlos, São Carlos, 2008. Rozenfeld (2007) STIERTORFER, K; GEHRING, W. (Hrsg.) Interkulturelle Kompetenz: Konzepte und Praxis des Unterrichts. Tübingen: Gunter Narr Verlag, p11- 47, 2002.

WEINRICH, H. Fremdsprachen als fremde Sprachen. In: WIERLACHER A. ALBRECHT, C. Fremdgänge: eine anthologische Fremdheitslehre für den Unterricht Deutsch als Fremdsprache. Bonn, Internationes, p.15-19, 1998.

WENDEN, A. Helping language learners think about learning. ELT Journal, v.40, n.1, p. 3-12, 1986. 